nurses and clinical assistants. 20 patients had biopsies with 17/20, $85 \%$ providing a diagnosis. Of the 102 appointments 13\% DNA; $11 \%$ cancelled by patient. Patients with vulval pain will be studied in more detail, data to follow (see abstract P160 table 1).

Conclusion The clinic was utilised by all staff groups, saw patients with a variety of conditions, predominantly dermatological and in the majority a definitive diagnosis was made. As well as improving patient management the clinic provided an excellent training opportunity and has resulted in improved links particularly with Dermatology and Histopathology.

Abstract P160 Table 1 Diagnoses of patients with complex GU problems

\begin{tabular}{|c|c|c|}
\hline & Presentation & Diagnosis \\
\hline \multirow[t]{8}{*}{ Women $(n=36)$} & Vulval pain-12 & $\begin{array}{l}\text { Vulvodynia-5, dermatitis-2, lichen sclerosis-1, } \\
\text { atrophic vulvitis-1, BV-1, psychological-1, } \\
\text { endometriosis-1 }\end{array}$ \\
\hline & Recurrent thrush-11 & Recurrent thrush-9, C.glabrata-1, lichen planus- 1 \\
\hline & Recurrent HSV-5 & Recurrent HSV-4, apthous ulceration- \\
\hline & Vulval itching-4 & Lichen simplex-1, eczema-1, NAD-2 \\
\hline & Lichen planus-1 & Lichen sclerosis-1 \\
\hline & Genital ulceration-1 & Recurrent HSV-1 \\
\hline & Recurrent BV-1 & Recurrent BV-1 \\
\hline & Vaginal discharge-1 & Referred for TVUSS-1 \\
\hline \multirow[t]{7}{*}{ Men $(n=29)$} & Genital dermatoses-19 & $\begin{array}{l}\text { Zoons balanitis- } 8 \text {, lichenoid reaction-2, } \\
\text { infective balanitis-2, eczema-2, seborrheic } \\
\text { dermatitis-1, lichen planus-1, lichen sclerosis }\end{array}$ \\
\hline & Persistent HPV-3 & Persistent HPV-3 \\
\hline & Recurrent NSU-2 & Chronic prostatitis-1; recurrent NSU-1 \\
\hline & AIN-1 & Sebaceous cyst-1 \\
\hline & Folliculitis-1 & Recurrent HSV-1 \\
\hline & Recurrent HSV-1 & Recurrent HSV-1 \\
\hline & Haematoma-1 & Resolved-1 \\
\hline
\end{tabular}

\section{P161 ROUTINE THREE-SITE NAAT TESTING IN MSM INCREASES PHARYNGEAL AND RECTAL DIAGNOSES OF CHLAMYDIA AND GONORRHOEA}

doi:10.1136/sextrans-2012-050601c.161

N Dufty, ${ }^{*}$ S Herbert, P French, D Mercey. Mortimer Market, London, UK

Background BASHH and Health Protection Agency guidelines acknowledge the increased sensitivity of Gonorrhoea (GC) NAAT testing compared to culture at extragenital sites. Chlamydia (CT) NAAT testing is also the test of choice at these sites. Routine threesite GC and CT testing in MSM was implemented at a genitourinary medicine clinic using urethral, pharyngeal and rectal sites.

Objectives To compare the number of diagnoses of CT and GC before and after implementation of routine three-site NAAT testing for MSM.

Methods Records were reviewed of MSM testing positive for CT or GC from the urethra, pharynx and/or rectum between 1 January 2010 and 1 April 2010 and compared to the same 3-month period in 2011.

Results Number of cases: The proportion of GC cultures resistant to $>1$ antibiotic increased from $15.9 \%(18 / 113)$ to $41.8 \%(28 / 67)$, however cultures were only taken in $51.1 \%(138 / 270)$ of NAAT positive GC specimens (see abstract P161 table 1 ).

Discussion Pharyngeal GC, CT and rectal GC diagnoses increased with three-site NAAT testing, making the pharynx and the rectum the main sites of GC and CT infection. This increase in diagnoses has implications for clinical service provision. The increase in antibiotic resistance to GC has important clinical implications and when using routine three-site NAAT testing, cultures should always be taken prior to antibiotics being given.
Abstract P161 Table 1 Comparison of CT/GC diagnosed

\begin{tabular}{|c|c|c|}
\hline & $012010^{*}$ & $012011 *$ \\
\hline MSM attendances & 4063 & 3975 \\
\hline MSM diagnosed & 166 & 354 \\
\hline Diagnoses of CT or GC & 199 & 494 \\
\hline CT (total) & 81 & 225 \\
\hline CT Urethra & 43 & 69 \\
\hline CT Pharynx & 0 & 32 \\
\hline CT Rectum & 25 & 113 \\
\hline LGV & 13 & 11 \\
\hline GC (total) & 118 & 269 \\
\hline GC Urethra & 58 & 45 \\
\hline GC Pharynx & 11 & 121 \\
\hline GC Rectum & 49 & 103 \\
\hline \multicolumn{3}{|l|}{ MSM with infection at } \\
\hline 1-site & $146(88 \%)$ & $258(72.9 \%)$ \\
\hline 2-site & $19(11.4 \%)$ & $80(22.6 \%)$ \\
\hline 3-site & $1(0.6 \%)$ & $16(4.5 \%)$ \\
\hline Diagnoses due to triple NAAT testing protocol (\% of total): & & 322 \\
\hline Pharyngeal CT & & $32(100 \%)$ \\
\hline Rectal CT & & $106(93.8 \%)$ \\
\hline Pharyngeal GC & & $109(90.1 \%)$ \\
\hline Rectal GC & & $75(72.8 \%)$ \\
\hline Diagnoses treated due to triple-site NAAT testing (\% of total) & & 234 \\
\hline Pharyngeal CT & & $20(62.5 \%)$ \\
\hline Rectal CT & & $78(69 \%)$ \\
\hline Pharyngeal GC & & $76(62.8 \%)$ \\
\hline Rectal GC & & $60(58.3 \%)$ \\
\hline
\end{tabular}

${ }^{*} 01$ 1st January to 1 st April.

\section{P162 STD PREVENTION ONLINE: A RESOURCE FOR THE STD/ STI PROFESSIONAL COMMUNITY}

doi:10.1136/sextrans-2012-050601c.162

C Rietmeijer. ${ }^{*}$ Colorado School of Public Health, Aurora, Colorado, USA

Background STDPreventionOnline.org (STDPO) is an online professional networking site for the sexually transmitted diseases/infections (STD/STI) work force, including researchers, clinicians, epidemiologists, disease intervention specialists, and programme managers. The site was developed by the internet and STD Center of Excellence, originally funded by a grant from the US Centers for Disease Control and Prevention (CDC) and currently sponsored by the American Sexually Transmitted Disease Association (ASTDA). The site was conceived as two-way clearing house of current STD/STI information and resources, where members could both download and upload information in a variety of formats including text, audio, and video files as well as blog and forum postings. Membership is free.

Objective To describe current users and usage of STPDPO.

Methods Descriptive statistics were obtained from embedded website metrics and Google Analytics $\odot$.

Results Since its inception in 2007, the site has registered 3500 members and the site's monthly newsletter has over 4000 subscribers. The predominance of site members (92\%) live/work in the US, however a substantial number ( $\mathrm{n}=258$ as of January 2012) are non-US users with 47 countries represented. Most members $(58 \%)$ work in STD/HIV programmes in state/local health departments, $13 \%$ in community or private clinics, $11 \%$ in a university setting, $8 \%$ in federal government, and $8 \%$ in community organisations. During 2011, the site logged 14778 individual site visits and 61205 page views; respectively 284 and 1177 per week. To date, over 